\title{
Effect of esterified 4-desmethylsterols and -stanols or 4,4'-dimethylsterols on cholesterol and bile acid metabolism in hamsters
}

\author{
Elke A. Trautwein ${ }^{1}$, Claudia Schulz ${ }^{2}$, Dörte Rieckhoff ${ }^{2}$, Angelika Kunath-Rau ${ }^{2}$, \\ Helmut F. Erbersdobler ${ }^{2}$, W. Arjan de Groot ${ }^{1}$ and Gert W. Meijer ${ }^{3}$ \\ ${ }^{1}$ Unilever Research, Vlaardingen, The Netherlands \\ ${ }^{2}$ University of Kiel, Institute of Human Nutrition and Food Science, Kiel, Germany \\ ${ }^{3}$ Lipton, 800 Sylvan Ave, Englewood Cliffs, New Jersey, USA
}

(Received 30 April 2001 - Revised 6 September 2001 - Accepted 6 November 2001)

\begin{abstract}
4-Desmethylsterols and -stanols reduce plasma total cholesterol (TC) and LDL cholesterol by inhibition of intestinal cholesterol absorption, while the cholesterol-lowering potential of 4,4'-dimethylsterols is less well defined. The present study aimed to compare the effects of 4-desmethylsterols, -stanols, and 4,4'-dimethylsterols on plasma and hepatic cholesterol, sterol excretion and bile acid metabolism. Male golden Syrian hamsters were fed diets containing $13 \mathrm{~g} / 100 \mathrm{~g}$ fat, $0.08 \mathrm{~g} / 100 \mathrm{~g}$ cholesterol and 0 (control), 0.24 or $0.48 \%$ (w/w) esterified 4-desmethylsterols (sterols) and esterified hydrogenated 4-desmethylsterols (stanols) from common vegetable oils or esterified $4,4^{\prime}$-dimethylsterols from rice bran oil for 5 weeks. Sterol and stanol esters at the dose of $0.24 \%$ were equally effective and significantly $(P<0.05)$ lowered TC by $15 \%$, while $0.24 \%$ 4,4-dimethylsterols reduced TC by $10 \%$. Liver total and esterified cholesterol concentrations were significantly $(P<0.05)$ lowered by $40,22,43$ and $31 \%$ in hamsters fed $0.48 \%$ sterols, $0.24 \%$ stanols, $0.48 \%$ stanols or $0.48 \%$ dimethylsterols, respectively. Daily faecal bile acid excretion and hepatic cholesterol $7 \alpha$-hydroxylase activity were not altered, indicating that sterols, stanols and dimethylsterols had no effect on the intestinal re-absorption of bile acids or on hepatic bile acid synthesis. Daily excretion of cholesterol was significantly higher in hamsters fed esterified sterols and stanols, but was only slightly increased in those fed dimethylsterols. The results indicate that esterified sterols and stanols were equally effective in lowering plasma TC and LDL cholesterol, while dimethylsterol esters caused a weaker cholesterol-lowering effect. Sterols and stanols achieve their cholesterol-lowering effect by stimulating faecal cholesterol excretion through inhibiting intestinal cholesterol absorption, but do not affect bile acid excretion. Other mechanisms need to be considered to explain the effect on plasma and hepatic cholesterol of dimethylsterols.
\end{abstract}

4-Desmethylsterols: 4-Desmethylstanols: 4,4'-Dimethylsterols: Plasma lipids: Bile acids: Faecal sterol excretion: Hamster

Plant sterols, also called phytosterols, are components of a normal diet, mainly coming from plant sources, e.g. vegetable oils, seeds, nuts and grain-based products. The typical consumption of plant sterols with Western diets ranges between 200 and $400 \mathrm{mg} / \mathrm{d}$, whereas the intake of phytostanols, the saturated form of plant sterols, is negligible (Jones et al. 1997). The most common plant sterols are the 4-desmethylsterols $\beta$-sitosterol, campesterol and stigmasterol; their saturated counterparts are sitostanol and campestanol.
The hypocholesterolaemic action of 4-desmethylsterols, i.e. of the predominant $\beta$-sitosterol, has been recognised since the early 1950s (Pollak \& Kritchevsky, 1981; Ling \& Jones, 1995a; Jones et al. 1997). Recently, interest has focused more on the cholesterol-lowering effect of plant stanols (Miettinen \& Vanhanen, 1994; Vanhanen et al. 1994; Gylling et al. 1995; Ling \& Jones, 1995b; Miettinen et al. 1995; Gylling \& Miettinen, 1996; Ntanios \& Jones, 1998; Nguyen et al. 1999). From data from animal studies, it was believed that sitostanol was more effective in

\footnotetext{
Abbreviations: apo, apolipoprotein; BC, biliary cholesterol; EC, esterified cholesterol; FC, free cholesterol; PL, phospholipid; TC, total cholesterol; TG, triacylglycerol.

*Corresponding author: Elke A. Trautwein, fax +31 10460 5993, email elke.trautwein@unilever.com
} 
lowering plasma cholesterol compared to sitosterol (Sugano et al. 1976, 1977; Ikeda et al. 1981). Recently, three human trials comparing directly esterified plant sterols $v$. plant stanols have clearly demonstrated that sterol esters are equally as effective as stanol esters in lowering total and LDL cholesterol in man (Weststrate \& Meijer, 1998; Hallikainen et al. 2000; Jones et al. 2000).

Sterols with other structures, e.g. 4,4'-dimethylsterols, may differ in their potential to lower plasma cholesterol concentrations. Rice bran oil contains 4,4'-dimethylsterols such as cycloartenol and 24-methylene cycloartenol as ferulic acid esters (oryzanol). Results from animal and some human studies suggest that these components may contribute to the hypocholesterolaemic effect of rice bran oil (DeDeckere \& Korver, 1996; Sugano \& Tsuji, 1997). However, results from two recent human studies on the hypocholesterolaemic effect of rice bran oil sterols are conflicting (Weststrate \& Meijer, 1998; Vissers et al. 2000).

It is generally assumed that plant sterols lower plasma cholesterol by inhibition of intestinal absorption of exogenous (dietary) and endogenous (biliary) cholesterol, although the exact mechanisms of action remain unclear. Whether plant sterols further influence the conversion of cholesterol into bile acids, e.g. via stimulation of cholesterol $7 \alpha$-hydroxylase activity, the key enzyme in bile acid synthesis is uncertain. Available data are conflicting, depending on whether sterols are infused intravenously or administered orally (Shefer et al. 1973, 1994; Boberg et al. 1989; Ling \& Jones, 1995a). In addition, little is known about the effects of 4-desmethylsterols and 4,4'-dimethylsterols on biliary lipid composition and the bile acid profile. The present study examined the effects of three different types of plant sterols, i.e. esterified 4-desmethylsterols, esterified hydrogenated 4-desmethylsterols (stanols) and esterified 4,4'-dimethylsterols, on cholesterol concentrations, and more especially on bile acid metabolism. This included bile acid composition, synthesis and excretion in cholesterol-fed hamsters and aimed to determine whether the structural differences of these sterols affect their cholesterol-lowering action. To our knowledge, this is the first time that esterified sterols, stanols and dimethylsterols have been directly compared. The Syrian golden hamster (Mesocricetus auratus ) was chosen because of its well-established similarities to human cholesterol and bile metabolism (Spady et al. 1985, 1986; Imray et al. 1992).

\section{Materials and methods}

\section{Animals}

A total of 96 male Syrian golden hamsters (SASCO, Omaha, NE, USA) weighing 71 (SD 4)g were randomly assigned to eight diet groups (twelve per group). Hamsters were housed in groups of four per cage in a temperaturecontrolled environment under a $12 \mathrm{~h}$ light-dark cycle (lights on 18.00 hours). The experimental protocol and procedures were approved by the Animal Care and Use Committee of the University of Kiel, Germany.

\section{Diets and feeding procedures}

Animals were fed semipurified diets for 5 weeks. The diets contained $130 \mathrm{~g} / \mathrm{kg}$ fat (30\% fat based on total energy) and $0 \%$ (cholesterol-free control diet) or $0.8 \mathrm{~g} / \mathrm{kg}$ cholesterol (cholesterol-rich control diet and all plant sterolsupplemented diets). The basal composition of the diet was as follows ( $\mathrm{g} / \mathrm{kg}$ dry weight): casein 200 , wheat starch 358 , glucose 150 , cellulose 100 , palm oil $59 \cdot 8$, olive oil $32 \cdot 2$, butter 26 , sunflower oil 13 , mineral mix 46 , vitamin mix 12, choline chloride 3 and cholesterol 0.8. The composition of the Ausman-Hayes mineral mix (F8530 BioServ, Frenchtown, NJ, USA) and the Hayes-Cathcart vitamin mix have been detailed previously (Hayes et al. 1989). The fatty acid composition of the diets resembled a typical Western fat intake with $13.8 \%$ saturated fatty acids, $12.2 \%$ monounsaturated fatty acids and $4.0 \%$ polyunsaturated fatty acids with polyunsaturated: saturated fatty acids of 0.33 . In the enriched diets, two doses, 2.4 or $4.8 \mathrm{~g} / \mathrm{kg}$, of (1) esterified 4-desmethylsterols from commonly used edible oil (mainly soyabean oil) distillates (Henkel Corporation, LaGrange, IL, USA), (2) esterified hydrogenated 4-desmethylsterols from the same source or (3) esterified 4,4'-dimethylsterols isolated by preparative chromatography after saponification from Oryzanol from rice bran oil (Tsuno, Wakayama, Japan) were added. All sterols had been esterified with fatty acids from rapeseed oil to an esterification degree of $>92 \%$ (Unilever Research Vlaardingen, The Netherlands). The 4-desmethylsterol, 4-desmethylstanol and 4,4'-dimethylsterol esters as well as the cholesterol were incorporated into the fat blend. By melting the sterol esters and the fat to approximately $60^{\circ} \mathrm{C}$, mixing and then cooling, a homogeneous mixture was obtained.

Hamsters were given free access to food and water and the food consumption per cage was recorded daily. Body weights were monitored on a weekly basis.

\section{Sample collection}

During week 4, faecal samples were collected over a $3 \mathrm{~d}$ period from eight randomly selected hamsters per diet to measure faecal neutral sterols and bile acid excretion. After 5 weeks, all hamsters were housed individually in wirebottomed cages and deprived of food for $18 \mathrm{~h}$ and then exsanguinated under anaesthesia using a gaseous mixture of $\mathrm{CO}_{2}: \mathrm{O}_{2}(50: 50)$. Blood samples were drawn into EDTA-wetted syringes by cardiac puncture and the liver, small intestine and caecum were excised, blotted and weighed. A portion of the liver was removed and frozen for hepatic cholesterol analysis. From eight randomly selected hamsters per diet group (hamsters fed the $0.48 \% 4,4^{\prime}$ dimethylsterol diet were not included, owing to lack of available rotor space), hepatic microsomes were isolated to measure microsomal cholesterol $7 \alpha$-hydroxylase activity. Gallbladder bile was aspirated, weighed and analysed for biliary lipids, biliary sterols and bile acid composition.

\section{Plasma lipid and lipoprotein analysis}

Plasma total cholesterol (TC) and triacylglycerol (TG) concentrations were determined by enzymic assays (Sigma 
Chemicals, Deisenhofen, Germany). For lipoprotein isolation, plasma $(1.6 \mathrm{ml})$ was either taken from a single hamster or pooled from two hamsters from the same dietary group with similar TC concentrations. Plasma lipoproteins were isolated by sequential ultracentrifugation (Havel et al. 1955). A preservation solution (final concentration in plasma: $1 \mathrm{mmol} / \mathrm{l}$ benzamidine, $0.04 \%$ EDTA, $0.005 \%$ gentamycin sulfate, $0.05 \% \mathrm{NaN}_{3}$ ) was added to protect lipoproteins from enzymic degradation. Three fractions were isolated based on the following densities (d): VLDL $(\mathrm{d}<1.006 \mathrm{~kg} / \mathrm{l})$, LDL $(1.006<\mathrm{d}<$ $1.055 \mathrm{~kg} / \mathrm{l})$, HDL $(1.055<\mathrm{d}<1.21 \mathrm{~kg} / \mathrm{l})$. With the exception of VLDL, lipoprotein fractions were dialysed against $0.15 \mathrm{~mol} / 1 \mathrm{NaCl}, 0.04 \%$ EDTA and $0.05 \% \mathrm{NaN}_{3}$ at $4^{\circ} \mathrm{C}$ for 24-36 h. TC, free cholesterol (FC), TG and phospholipid (PL) concentrations were determined using enzymic assays (for TC and TG, kits from Sigma Chemicals; for FC and PL, kits from Wako Chemicals, Düsseldorf, Germany). Protein concentration was determined by a modification of the Lowry procedure (Markwell et al. 1978). The density cut-off points were verified in previous experiments by checking for cross-contamination; LDL and HDL apolipoproteins (apo) were separated by gradient SDS-PAGE (4$20 \%$ ) and stained with Coomassie Brilliant Blue. No traces of apo $\mathrm{B}_{100}$ were present in the HDL fractions, while LDL fractions contained traces of apo $\mathrm{A}_{1}$. A previous characterisation of apo $\mathrm{B}$ - and $\mathrm{A}_{1}$-containing lipoprotein fractions of the hamster demonstrated that dense LDL-like particles overlapped apo $\mathrm{A}_{1}$-containing $\mathrm{HDL}$ particles in the density range from 1.039 to 1.074 (Goulinet \& Chapman, 1993).

\section{Hepatic cholesterol analysis}

Cholesterol concentrations were analysed following the procedure described in detail previously (Trautwein et al. 1993b). TC was determined with an enzymic assay and FC was analysed by HPLC. Esterified cholesterol (EC) concentrations were calculated as the difference between $\mathrm{TC}$ and $\mathrm{FC}$.

\section{Bile analysis}

Biliary cholesterol (BC) and PL were determined using an enzymic assay (Wako Chemicals). Bile acids were analysed in an aliquot of the methanol/ $\mathrm{KCl}$ phase after Folch extraction as taurine- and glycine-conjugated bile acids by HPLC (Rossi et al. 1987). Total bile acid concentration was calculated as the sum of individual bile acids (taurine and glycine conjugates of cholate, chenodeoxycholate, deoxycholate and lithocholate).

\section{Hepatic cholesterol $7 \alpha$-hydroxylase activity}

Hepatic microsomes were isolated by ultracentrifugation as previously described (Hylemon et al. 1989) and stored at $-80^{\circ} \mathrm{C}$. Microsomal protein was determined using a modified Lowry procedure (Markwell et al. 1978). Hepatic cholesterol $7 \alpha$-hydroxylase activity was determined by HPLC after enzymic conversion to $7 \alpha$-hydroxy-4-cholesten3-one using cholesterol oxidase (Chiang, 1991).

\section{Determination of faecal bile acids and sterols}

Faecal sterols and total bile acid concentrations were analysed in an oven-dried faecal sample using a modification of the method of Suckling et al. (1991). Faecal total bile acid concentration was determined using an enzymic assay (Sigma bile acid kit; Sigma Chemicals) with some modifications. Faecal sterols including plant sterols, stanols and dimethylsterols and neutral sterols (cholesterol plus breakdown products) were analysed by GC as free (unsilylated) sterols as previously detailed (Trautwein et al. 1997). A dried sample of each diet was

Table 1. Plasma cholesterol and triacylglycerol concentrations of hamsters fed on diets containing $0 \%$ cholesterol and $0 \%$ plant sterols or $0.08 \%$ cholesterol plus $0,0.24$ or $0.48 \%$ 4-desmethylsterols, hydrogenated 4-desmethylsterols (stanols) or 4,4'-dimethylsterols for 5 weeks $\dagger$ (Mean values and standard deviations of twelve hamsters per diet for TC and TG and of five to six hamsters per diet for VLDL, LDL and HDL)

\begin{tabular}{|c|c|c|c|c|c|c|c|c|c|c|c|c|}
\hline \multirow{3}{*}{ Diet ... } & \multicolumn{8}{|c|}{ Cholesterol (C) (mmol/l) } & \multicolumn{4}{|c|}{ Triacylglycerol (TG) (mmol/l) } \\
\hline & \multicolumn{2}{|c|}{$\mathrm{TC}$} & \multicolumn{2}{|c|}{ VLDL-C } & \multicolumn{2}{|c|}{ LDL-C } & \multicolumn{2}{|c|}{ HDL-C } & \multicolumn{2}{|c|}{ TG } & \multicolumn{2}{|c|}{ VLDL-TG } \\
\hline & Mean & SD & Mean & SD & Mean & SD & Mean & SD & Mean & SD & Mean & SD \\
\hline \multicolumn{13}{|l|}{$0 \%$ cholesterol } \\
\hline $\begin{array}{c}0 \% \text { sterols }^{*} \\
0.08 \% \text { cholesterol }^{2}\end{array}$ & $4 \cdot 77$ & 0.37 & 1.03 & 0.26 & 0.40 & 0.03 & $3 \cdot 31$ & 0.27 & 3.42 & 1.02 & $2 \cdot 91$ & $0 \cdot 74$ \\
\hline $0 \%$ sterols & $6 \cdot 26^{c}$ & 0.65 & 1.57 & 0.42 & $0.70^{\mathrm{b}}$ & 0.20 & 3.99 & 0.28 & 4.99 & 1.90 & $3.86^{a b c}$ & 0.93 \\
\hline $0.24 \%$ sterols & $5 \cdot 34^{\mathrm{ab}}$ & 0.57 & 1.09 & 0.14 & $0.44^{\mathrm{a}}$ & 0.08 & 3.60 & 0.22 & 4.06 & 1.56 & $2 \cdot 69^{a}$ & 0.37 \\
\hline $0.48 \%$ sterols & $5 \cdot 70^{\mathrm{ab}}$ & 0.52 & 1.43 & 0.14 & $0.51^{\mathrm{ab}}$ & 0.14 & 3.68 & 0.25 & 4.82 & $2 \cdot 21$ & $4 \cdot 16^{\mathrm{bc}}$ & 0.74 \\
\hline $0.24 \%$ stanols & $5 \cdot 29^{\mathrm{a}}$ & 0.43 & $1 \cdot 21$ & 0.34 & $0.46^{\mathrm{a}}$ & 0.07 & 3.63 & 0.32 & 3.48 & 1.29 & $2 \cdot 91^{\mathrm{ab}}$ & 0.86 \\
\hline $0.48 \%$ stanols & $5 \cdot 32^{\mathrm{ab}}$ & 0.41 & $1 \cdot 18$ & 0.34 & $0.53^{\mathrm{ab}}$ & 0.09 & 3.85 & 0.25 & 3.74 & 1.24 & $3.25^{\mathrm{abc}}$ & 0.91 \\
\hline $0.24 \% 4,4^{\prime}$-dimethylsterols & $5 \cdot 62^{\mathrm{ab}}$ & 0.52 & 1.47 & 0.30 & $0.55^{\mathrm{ab}}$ & 0.05 & 4.00 & 0.17 & 3.48 & 1.18 & $3.65^{\mathrm{abc}}$ & 0.75 \\
\hline $0.48 \% 4,4^{\prime}$-dimethylsterols & $5 \cdot 95^{\mathrm{bc}}$ & 0.52 & 1.58 & 0.25 & $0.60^{\mathrm{ab}}$ & 0.06 & $3 \cdot 81$ & 0.27 & 3.72 & $1 \cdot 12$ & $4 \cdot 34^{\mathrm{C}}$ & 0.71 \\
\hline
\end{tabular}

TC, total cholesterol.

a,b,c Values in a column with unlike superscripts were significantly different $(P<0.05)$ as determined by one-way ANOVA and the Student-Neuman-Keuls post hoc test.

* This group was not included in the statistical analysis.

†For details of diets see p. 228. 
analysed for cholesterol and phytosterol concentration applying the same method as described for the faecal samples.

\section{Statistical analysis}

All results are expressed as mean and standard deviation. Statistical differences were calculated using ANOVA followed by the Student-Neuman-Keuls post hoc test. The group receiving the cholesterol-free control diet was not included in the statistical analysis. Differences between diet groups were considered significant at $P<0 \cdot 05$. All statistical analyses were performed using the Super ANOVA statistical software package (Abacus Concepts, Berkely, CA, USA).

\section{Results}

\section{Food intake, body weight gain and organ weights}

Food intake, final body weights, body weight gain and relative weights of the small intestine and the caecum were similar between groups (data not shown). Absolute liver weights were also similar between groups, but relative liver weights of hamsters fed the diets supplemented with $0.24 \%$ sterols, $0.24 \%$ stanols and $0.48 \%$ stanols were significantly lower $(4 \cdot 3(\mathrm{SD} 0 \cdot 3), 4.3$ (SD 0.2), 4.3 (SD 0.2) $\mathrm{g} / 100 \mathrm{~g}$ body weight, respectively) than those of the cholesterol-fed control animals (4.7 (SD 0.5) g/100 g body weight).

\section{Plasma lipids and lipoproteins}

After 5 weeks plasma TC concentrations were significantly lower $(-15 \%)$ in hamsters fed $0.24 \%$ plant sterols, $0.24 \%$ and $0.48 \%$ plant stanols compared to those fed the cholesterol-containing control diet (Table 1). TC was 9\% lower in hamsters fed $0.48 \%$ plant sterols compared to controls, but this was not statistically significant. The cholesterol-lowering effect was not dose-dependent. The lower dose $(0.24 \%)$ of $4,4^{\prime}$-dimethylsterols significantly lowered TC compared with controls $(-10 \%)$, while doubling the dose to $0.48 \%$ did not lower TC significantly. Plasma TG concentrations were up to $30 \%$ lower in hamsters fed the sterol-, stanol- and dimethylsterolsupplemented diets, but owing to a large intra-individual variation the effect did not reach the level of statistical significance $(P=0 \cdot 095)$ (Table 1$)$.

Plasma VLDL and HDL cholesterol concentrations did not differ among the groups, while LDL cholesterol concentrations were significantly lower in hamsters fed $0.24 \%$ plant sterols and $0.24 \%$ stanols (Table 1 ). When expressed as a percentage of TC, no differences in the relative distribution of VLDL, LDL and HDL cholesterol was found. Most cholesterol was present as HDL cholesterol (64-70\%). Compared to cholesterol-fed controls, VLDL TG concentrations tended to be lower in hamsters fed $0.24 \%$ sterols or $0.24 \%$ stanols (Table 1). No relevant changes were observed in the composition of VLDL, LDL and HDL (data not shown).

\section{Hepatic cholesterol}

TC and EC concentrations were significantly lower in livers of hamsters fed $0.48 \%$ plant sterols, $0.24 \%$ and $0.48 \%$ stanols and $0.48 \%$ 4, $4^{\prime}$-dimethylsterols compared with cholesterol-fed control hamsters, while $0.24 \%$ sterols and $0.24 \%$ 4,4'-dimethylsterols decreased liver TC accumulation non-significantly (Table 2). The effect produced by $0.48 \%$ plant sterols and $0.48 \%$ stanols was comparable. Hepatic FC concentrations did not differ between groups.

Table 2. Hepatic cholesterol concentrations ( $\mu \mathrm{mol} / \mathrm{g}$ liver) of hamsters fed on diets containing $0 \%$ cholesterol and $0 \%$ plant sterols or $0.08 \%$ cholesterol plus $0,0.24$ or $0.48 \%$ 4-desmethylsterols, hydrogenated 4-desmethylsterols (stanols) or 4,4'-dimethylsterols for 5 weeks $\dagger$

(Mean values and standard deviations of twelve hamsters per diet)

\begin{tabular}{|c|c|c|c|c|c|c|c|c|c|c|}
\hline \multirow{2}{*}{ Diet ... } & \multicolumn{2}{|c|}{$\begin{array}{l}\text { Total cholesterol } \\
\text { (TC) }\end{array}$} & \multicolumn{2}{|c|}{$\begin{array}{c}\text { Free } \\
\text { cholesterol }\end{array}$} & \multicolumn{2}{|c|}{$\%$ TC } & \multicolumn{2}{|c|}{$\begin{array}{l}\text { Esterified } \\
\text { cholesterol }\end{array}$} & \multicolumn{2}{|c|}{$\%$ TC } \\
\hline & Mean & SD & Mean & SD & Mean & SD & Mean & SD & Mean & SD \\
\hline \multicolumn{11}{|l|}{$0 \%$ cholesterol } \\
\hline $0 \%$ sterols $^{*}$ & $14 \cdot 84$ & $3 \cdot 67$ & $7 \cdot 12$ & 0.77 & $51^{d}$ & 14 & $7 \cdot 71$ & $3 \cdot 80$ & 49 & 13 \\
\hline \multicolumn{11}{|l|}{$0.08 \%$ cholesterol } \\
\hline $0 \%$ sterols & $67 \cdot 01^{d}$ & 9.62 & 8.08 & 1.04 & $12^{\mathrm{a}}$ & 1 & $58.93^{d}$ & 8.96 & $88^{d}$ & 1 \\
\hline $0.24 \%$ sterols & $60 \cdot 90^{\mathrm{cd}}$ & 11.77 & $8 \cdot 21$ & 1.41 & $14^{\mathrm{ab}}$ & 2 & $52 \cdot 69^{\mathrm{cd}}$ & 11.07 & $86^{\mathrm{cd}}$ & 2 \\
\hline $0.48 \%$ sterols & $40 \cdot 19^{a}$ & $9 \cdot 24$ & 8.09 & 1.31 & $21^{d}$ & 5 & $32 \cdot 10^{\mathrm{a}}$ & $9 \cdot 20$ & $79^{a}$ & 5 \\
\hline $0.24 \%$ stanols & $52 \cdot 45^{\mathrm{bc}}$ & 12.51 & $8 \cdot 23$ & 0.94 & $16^{\mathrm{bc}}$ & 3 & $44 \cdot 22^{\mathrm{bc}}$ & $12 \cdot 38$ & $84^{\mathrm{bc}}$ & 3 \\
\hline $0.48 \%$ stanols & $38 \cdot 32^{\mathrm{a}}$ & $6 \cdot 20$ & $8 \cdot 18$ & $1 \cdot 10$ & $22^{d}$ & 3 & $30 \cdot 15^{\mathrm{a}}$ & 5.62 & $78^{\mathrm{a}}$ & 3 \\
\hline $0.24 \% 4,4^{\prime}$-dimethylsterols & $58 \cdot 53^{\mathrm{cd}}$ & 5.06 & 8.58 & 1.38 & $15^{\mathrm{ab}}$ & 3 & $49.94^{c}$ & 5.40 & $85^{\mathrm{cd}}$ & 3 \\
\hline $0.48 \% 4,4^{\prime}$-dimethylsterols & $46 \cdot 27^{\mathrm{ab}}$ & 8.58 & 8.45 & 1.02 & $19^{\text {cd }}$ & 3 & $37 \cdot 82^{\mathrm{ab}}$ & $8 \cdot 27$ & $81^{\mathrm{ab}}$ & 3 \\
\hline
\end{tabular}

a,b,c,d Values in a column with unlike superscripts were significantly different $(P<0.05)$ as determined by one-way ANOVA and the Student-NeumanKeuls post hoc test.

* This group was not included in the statistical analysis.

†For details of diets see p. 228. 


\section{Biliary lipids and bile acid profile}

The total lipid concentrations in bile did not differ among groups (data not shown). Neither the concentrations (mmol/l), nor the molar percentages $(\mathrm{mol} / 100 \mathrm{~mol}$ total lipids) of biliary bile acids and PL were altered in hamsters fed on diets enriched with different types of plant sterol esters compared with controls (Table 3). However, the molar percentage of $\mathrm{BC}$ was lower in hamsters fed 0.24 and $0.48 \%$ stanols $(-19$ and $-10 \%$, respectively) than in those fed the cholesterol-rich control diet, although this was statistically significant only for the lower dose (Table 3 ). No differences in the concentrations of individual bile acids in gallbladder bile were found in hamsters fed the different diets (data not shown). In addition, no major alterations were observed in the relative molar percentages of individual bile acids (Table 4). However, the molar percentage of total cholate (sum of tauro- and glycocholic acid) was significantly higher in bile from hamsters fed on diets supplemented with the two doses $(0.24$ and $0.48 \%)$ of plant sterols, stanols and 4,4'-dimethylsterols. In contrast, the molar percentage of total chenodeoxycholate (sum of tauro- and glycochenodeoxycholic acid) was lower, but the decrease was statistically significant only in hamsters fed $0.48 \%$ sterols or stanols (Table 4 ). As a result of these changes in the bile acid profile, cholate: chenodeoxycholate was significantly higher in hamsters fed $0.48 \%$ plant sterols, 0.24 and $0.48 \%$ stanols and $0.24 \% 4,4^{\prime}$ dimethylsterols (Table 4). The glycine:taurine conjunction ratio as well as the ratio of primary:secondary bile acids did not differ among groups (Table 4).

\section{Activities of cholesterol $7 \alpha$-hydroxylase}

No difference in the activity of microsomal cholesterol $7 \alpha$ hydroxylase was observed between hamsters fed the cholesterol-free and cholesterol-containing control diets (22.1 (SD 10.0) and 18.2 (SD 7.4) $\mathrm{pmol} / \mathrm{h}$ and $\mathrm{mg}$ protein, respectively). Further cholesterol $7 \alpha$-hydroxylase activity was not significantly different in animals fed the two doses $(0.24$ and $0.48 \%)$ of plant sterol and stanol esters or $0.24 \%$ 4,4'-dimethylsterol esters (17.5 (SD 5.1), 19.4 (SD 6.9), 18.6 (SD 6.1), 23.2 (SD 6.8), 22.8 (SD 9.8) $\mathrm{pmol} / \mathrm{h}$ and $\mathrm{mg}$ protein, respectively).

\section{Faecal output and faecal bile acid excretion}

The daily faecal output (g dry faeces) was non-significantly higher $(15-40 \%)$ in hamsters fed plant sterols or stanols compared to cholesterol-fed control animals. Hamsters fed $0.48 \%$ 4,4'-dimethylsterols had a significantly higher faecal output than the cholesterol-fed controls (Table 5). The faecal concentration of bile acids ( $\mu \mathrm{mol} / \mathrm{g}$ ) was $13-28 \%$ lower in hamsters fed diets with different types of plant sterol esters compared to cholesterol-fed controls, but this was statistically significant only in hamsters fed $0.24 \%$ sterols, $0.48 \%$ stanols as well as 0.24 and $0.48 \%$ 4,4'-dimethylsterols (Table 5). Daily bile acid excretion, however, did not differ among the groups (Table 5).

\section{Faecal sterol excretion}

The daily faecal excretion of neutral sterols (cholesterol, coprostanol, cholestanol and coprostanone) was significantly higher in hamsters fed the sterol- and stanolsupplemented diets, but not in those fed $4,4^{\prime}$-dimethylsterols compared to cholesterol-fed controls (Fig. 1). This was mainly the result of the significantly higher faecal cholesterol concentration while coprostanol concentrations were unchanged (data not shown). Cholesterol and

Table 3. Biliary lipid concentration (bile acids, phospholipids and biliary free cholesterol) of hamsters fed diets containing $0 \%$ cholesterol and $0 \%$ plant sterols or $0.08 \%$ cholesterol plus $0,0.24$ or $0.48 \% 4$-desmethylsterols, hydrogenated 4 -desmethylsterols (stanols) or $4,4^{\prime}$-dimethyldimethylsterols for 5 weeks $\dagger$

(Mean values and standard deviations of twelve hamsters per diet)

\begin{tabular}{|c|c|c|c|c|c|c|c|c|c|c|c|c|}
\hline \multirow{3}{*}{ Diet ... } & \multicolumn{4}{|c|}{ Bile acids } & \multicolumn{4}{|c|}{ Phospholipids } & \multicolumn{4}{|c|}{ Cholesterol } \\
\hline & \multicolumn{2}{|c|}{$\mathrm{mmol} / \mathrm{l}$} & \multicolumn{2}{|c|}{$\mathrm{mol} \%^{3} \ddagger$} & \multicolumn{2}{|c|}{$\mathrm{mmol} / \mathrm{l}$} & \multicolumn{2}{|c|}{$\mathrm{mol} \%$} & \multicolumn{2}{|c|}{$\mathrm{mmol} / \mathrm{l}$} & \multicolumn{2}{|c|}{$\mathrm{mol} \% \ddagger$} \\
\hline & Mean & SD & Mean & SD & Mean & SD & Mean & SD & Mean & SD & Mean & SD \\
\hline \multicolumn{13}{|l|}{$0 \%$ cholesterol } \\
\hline $0 \%$ sterols $^{\star}$ & 185 & 28 & $88 \cdot 4$ & $1 \cdot 7$ & $20 \cdot 8$ & $3 \cdot 8$ & $9 \cdot 9$ & 1.4 & $3 \cdot 4$ & 0.7 & $1 \cdot 6$ & 0.3 \\
\hline \multicolumn{13}{|l|}{$0.08 \%$ cholesterol } \\
\hline $0 \%$ sterols & 179 & 42 & $88 \cdot 2$ & 1.4 & $19 \cdot 7$ & 5.4 & $9 \cdot 7$ & $1 \cdot 2$ & $4 \cdot 3^{b c}$ & $1 \cdot 2$ & $2 \cdot 1^{\mathrm{bc}}$ & 0.3 \\
\hline $0.24 \%$ sterols & 180 & 28 & 87.4 & $1 \cdot 6$ & $21 \cdot 1$ & $4 \cdot 0$ & $10 \cdot 3$ & 1.4 & $4 \cdot 8^{\mathrm{bc}}$ & $1 \cdot 1$ & $2 \cdot 3^{c}$ & 0.3 \\
\hline $0.48 \%$ sterols & 180 & 35 & 87.9 & 2.5 & $19 \cdot 7$ & $4 \cdot 2$ & $9 \cdot 9$ & $2 \cdot 3$ & $4 \cdot 6^{\mathrm{bc}}$ & 0.9 & $2 \cdot 2^{\mathrm{c}}$ & 0.3 \\
\hline $0.24 \%$ stanols & 168 & 46 & $88 \cdot 4$ & $1 \cdot 6$ & $18 \cdot 8$ & $5 \cdot 6$ & 9.9 & 1.5 & $3 \cdot 2^{\mathrm{a}}$ & $1 \cdot 1$ & $1 \cdot 7^{\mathrm{a}}$ & 0.4 \\
\hline $0.48 \%$ stanols & 187 & 34 & 88.7 & $1 \cdot 1$ & $19 \cdot 7$ & $3 \cdot 6$ & 9.4 & 0.9 & $3.9^{a b}$ & 1.0 & $1.9^{a b}$ & 0.4 \\
\hline $0.24 \% 4,4^{\prime}$-dimethylsterols & 165 & 32 & 87.5 & 1.8 & $19 \cdot 2$ & $4 \cdot 3$ & $10 \cdot 2$ & 1.6 & $4 \cdot 3^{b c}$ & 0.9 & $2 \cdot 3^{C}$ & 0.3 \\
\hline $0.48 \% 4,4^{\prime}$-dimethylsterols & 189 & 20 & $87 \cdot 2$ & 1.9 & $22 \cdot 7$ & 4.3 & $10 \cdot 4$ & 1.7 & $5 \cdot 2^{\mathrm{c}}$ & 0.9 & $2 \cdot 4^{\mathrm{c}}$ & 0.3 \\
\hline
\end{tabular}

${ }^{a, b, c}$ Values in a column with unlike superscripts were significantly different $(P<0.05)$ as determined by one-way ANOVA and the Student-Neuman-Keuls post hoc test.

* This group was not included in the statistical analysis.

†For details of diets see p. 228.

$\ddagger \mathrm{mol} \%, \mathrm{~mol} / 100 \mathrm{~mol}$ total biliary lipids. 
coprostanol were the two major sterols excreted in the faeces.

Plant sterol, stanol and 4,4'-dimethylsterol concentrations measured in the faecal sample reflected the sterol pattern of the supplemented diets. As expected, daily faecal sterol, stanol and 4,4'-dimethylsterol excretion was significantly higher in hamsters fed the enriched diets than in controls (Fig. 2). Daily excretion of sterols, stanols or 4,4'-dimethylsterols was significantly higher in hamsters fed the 0.48 v. $0.24 \%$ dose, although there was a large intra-animal variation (Fig. 1).

\section{Discussion}

The present study examined for the first time the effects of three different types of plant sterols (at two doses of $0.24 \mathrm{v}$. $0.48 \%$ ), i.e. esterified 4-desmethylsterols (sterols), hydrogenated 4-desmethylsterols (stanols) and 4,4'-dimethylsterols on plasma cholesterol concentrations. In addition, aspects of bile acid metabolism, in particular bile acid pattern, synthesis and excretion, were assessed and data on bile acid profile in gallbladder bile are presented.

In the present study with hamsters fed on cholesterolenriched diets $(0.08 \%$ dietary cholesterol $)$ esters of 4-desmethylsterols and -stanols significantly $(P<0.05)$ lowered TC and LDL cholesterol. Both had equal cholesterol-lowering effects resulting in a $15 \%$ reduction in TC with a dose of $0 \cdot 24 \% \cdot 4,4^{\prime}$-Dimethylsterol esters at a dose of $0.24 \%$ significantly $(P<0.05)$ lowered TC by $10 \%$, but were altogether less effective in lowering TC compared to desmethylsterol esters. This finding is similar to previous findings in human trials (Weststrate \& Meijer, 1998; Sierksma et al. 1999; Vissers et al. 2000).

With regard to hepatic cholesterol accumulation, esterified dimethylsterols significantly $(P<0.05)$ lowered TC and EC concentrations in the liver. However, the effect was again less than seen with desmethylsterols or -stanols. The weaker effect of 4,4'-dimethylsterols could possibly relate to their chemical structure. 4-Desmethylsterols such as $\beta$-sitosterol and campesterol are similar to cholesterol, differing only in a side-chain substitution, while $4,4^{\prime}$ dimethylsterols such as cycloartenol also have two additional methyl groups at the site adjacent to the hydroxyl group. Despite the reductions seen in plasma and liver cholesterol, faecal cholesterol excretion was only moderately enhanced in hamsters fed the dimethylsterolenriched diets. Similar to the present findings, Ikeda et al. (1985) found in rats that hepatic cholesterol accumulation was mitigated by cycloartenol, while no effect on TC was seen. Further, cycloartenol was also less effective than $\beta$ sitosterol in enhancing faecal sterol excretion, similar to the observations in the present hamster study. Interestingly, cycloartenol was absorbed at a 4-fold higher rate than $\beta$ sitosterol (Ikeda et al. 1985). Since 4,4'-dimethylsterols had only minor effects on faecal cholesterol excretion, it is unlikely that the primary mechanism for the cholesterollowering actions of these sterols is a diminished intestinal cholesterol absorption via interference with micellar solubilisation of cholesterol, as suggested by others (Nagao et al. 2001). Therefore, as suggested by Ikeda et al. (1985), post-absorptive, secondary effects such as an 
Table 5. Faecal excretion, faecal bile and concentration and daily faecal bile acid excretion in hamsters fed on diets containing $0 \%$ cholesterol and $0 \%$ plant sterols or $0.08 \%$ cholesterol plus $0,0.24$ or $0.48 \%$ 4-desmethylsterols, hydrogenated 4-desmethylsterols (stanols) or 4,4'-dimethylsterols for 5 weeks. † Faecal samples were collected over a $3 \mathrm{~d}$ period during week 4 . Hamsters were randomly selected and housed individually in wire-bottomed cages during faecal collection

(Mean values and standard deviations of eight hamsters per diet)

\begin{tabular}{|c|c|c|c|c|c|c|}
\hline \multirow[b]{2}{*}{ Diet ... } & \multicolumn{2}{|c|}{$\begin{array}{c}\text { Faecal } \\
\text { excretion (g/d } \\
\text { (dry wt)) }\end{array}$} & \multicolumn{2}{|c|}{$\begin{array}{c}\text { Bile acid } \\
\text { concentration } \\
\text { ( } \mu \text { mol } / \mathrm{g} \text { dry } \\
\text { faeces })\end{array}$} & \multicolumn{2}{|c|}{$\begin{array}{l}\text { Daily bile acid } \\
\text { excretion } \\
(\mu \mathrm{mol} / \mathrm{d})\end{array}$} \\
\hline & Mean & SD & Mean & SD & Mean & SD \\
\hline \multicolumn{7}{|l|}{$0 \%$ cholesterol } \\
\hline $0 \%$ sterols $^{*}$ & 0.76 & 0.19 & $2 \cdot 65$ & 0.40 & $2 \cdot 06$ & 0.69 \\
\hline \multicolumn{7}{|l|}{$0.08 \%$ cholesterol } \\
\hline $0 \%$ sterols & $0.75^{\mathrm{a}}$ & 0.15 & $3.42^{\mathrm{b}}$ & 0.71 & 2.51 & 0.57 \\
\hline $0.24 \%$ sterols & $0.87^{\mathrm{ab}}$ & 0.13 & $2 \cdot 46^{\mathrm{a}}$ & 0.43 & $2 \cdot 12$ & 0.32 \\
\hline $0.48 \%$ sterols & $0.96^{\mathrm{ab}}$ & 0.14 & $2 \cdot 96^{\mathrm{ab}}$ & 0.33 & $2 \cdot 83$ & 0.46 \\
\hline $0.24 \%$ stanols & $0.86^{\mathrm{ab}}$ & 0.18 & $2 \cdot 87^{\mathrm{ab}}$ & 0.25 & 2.48 & 0.55 \\
\hline $0.48 \%$ stanols & $0.95^{\mathrm{ab}}$ & 0.14 & $2 \cdot 68^{a}$ & 0.34 & 2.55 & 0.40 \\
\hline $0.24 \% 4,4^{\prime}$-dimethylsterols & $0.90^{\mathrm{ab}}$ & 0.11 & $2 \cdot 62^{\mathrm{a}}$ & 0.48 & $2 \cdot 37$ & 0.50 \\
\hline $0.48 \% 4,4^{\prime}$-dimethylsterols & $1.06^{\mathrm{b}}$ & 0.24 & $2 \cdot 73^{a}$ & 0.62 & $2 \cdot 87$ & 0.98 \\
\hline
\end{tabular}

a,b,c Values in a column with unlike superscripts were significantly different $(P<0.05)$ as determined by one-way ANOVA and the Student-Neuman-Keuls post hoc test.

* This group was not included in the statistical analysis.

†For details of diets see p. 228.

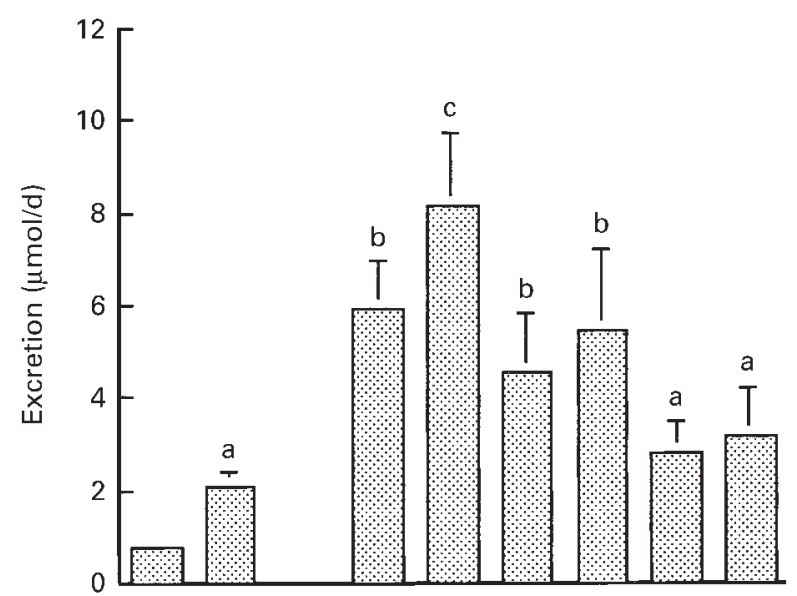

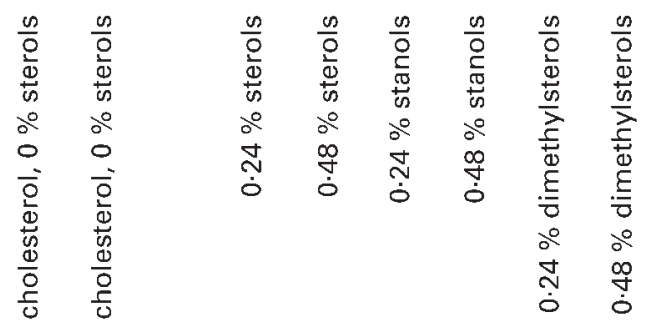

Fig. 1. Daily excretion of neutral sterols (cholesterol plus coprostanol, cholestanol and coprostanone) of hamsters fed diets containing $0 \%$ cholesterol and $0 \%$ plant sterols or $0.08 \%$ cholesterol plus 0 , 0.24 or $0.48 \%$ 4-desmethylsterols, hydrogenated 4-desmethylsterols (stanols) or 4,4'-dimethylsterols. Values are means with their standard deviations represented by vertical bars $(n 8)$. Values with unlike superscript letters were significantly different $(P>0.05)$ as determined by the Student-Neuman-Keuls post hoc test after ANOVA. The group containing no cholesterol (control group) was not included in the statistical analysis.

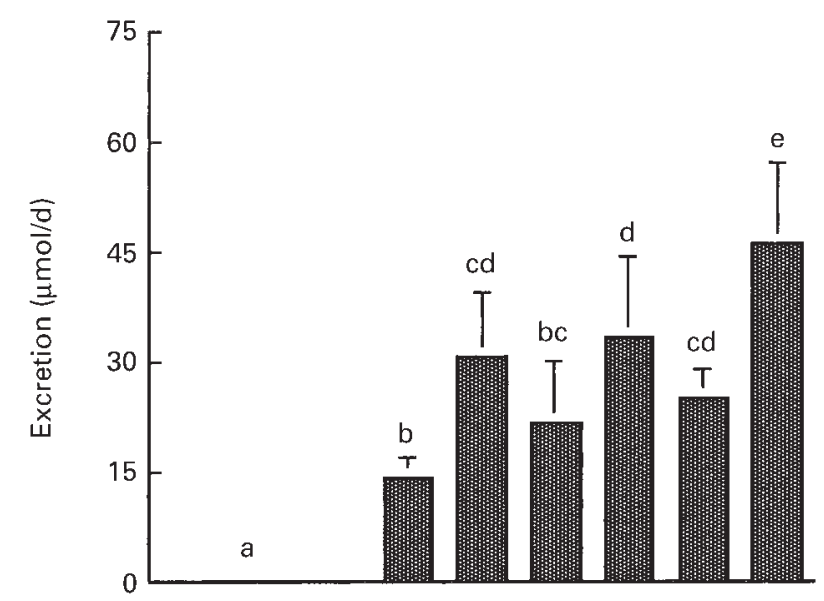

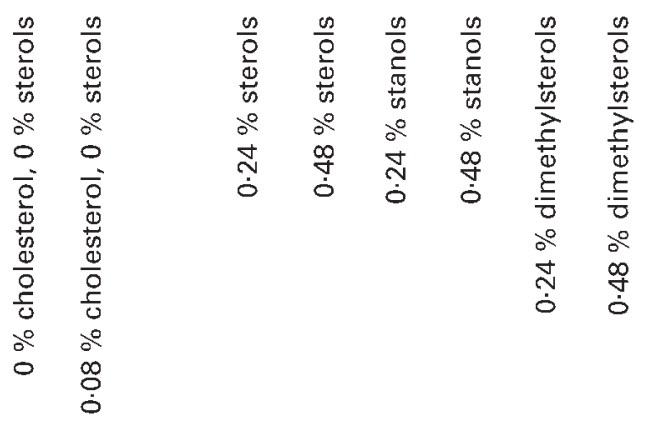

Fig. 2. Daily excretion of phytosterols, -stanols or dimethylsterols of hamsters fed diets containing $0 \%$ cholesterol and $0 \%$ plant sterols or $0.08 \%$ cholesterol plus $0,0.24$ or $0.48 \% 4$-desmethylsterols, hydrogenated 4-desmethylsterols (stanols) or 4,4'-dimethylsterols. Values are means with their standard deviations represented by vertical bars $(n 8)$. Values with unlike superscript letters were significantly different $(P>0.05)$ as determined by the Student-NeumanKeuls post hoc test after ANOVA. The group containing no cholesterol (control group) was not included in the statistical analysis. 
inhibitory effect on cholesterol biosynthesis or a hormonelike effect might explain the cholesterol-lowering action of cycloartenol and other 4,4'-dimethylsterols. Recently, Nagao et al. (2001) found a reduction in serum and liver cholesterol and a significant increase in faecal cholesterol excretion in rats fed on rice bran oil or unsaponifiable compounds prepared from rice bran oil. In addition, no significant effects on the mRNA abundances for various cholesterol metabolism-related proteins (3-hydroxy-3methylglutaryl CoA reductase, LDL receptor or cholesterol $7 \alpha$-hydroxylase) were observed, and it was concluded that interrupting the intestinal absorption of cholesterol was the main mechanism for the cholesterol-lowering action of rice bran oil sterols (Nagao et al. 2001). However, rice bran oil and the unsaponifiable compounds of rice bran oil used in that study contained mainly desmethylsterols (mostly in the form of $\beta$-sitosterol) and only minor amounts of dimethylsterols. Therefore, the observed effects seem more attributable to desmethylsterols rather than dimethylsterols.

The differences between 0.24 and $0.48 \%$ plant sterol and stanol ester diets on plasma cholesterol concentrations were not significant $(P>0 \cdot 05)$. The differences were significant $(P<0.05)$ for hepatic cholesterol, for which a dose-dependent reduction was seen. The lack of a striking dose-response effect is not likely to be linked to the animal model, the cholesterol level of the diet or the duration of the study. The hamster is a suitable animal model to study effects on cholesterol metabolism and a 5-week feeding period is sufficient to reach a new metabolic steady stage condition (Kris-Etherton \& Dietschy, 1997). Moreover, $0.08 \%$ dietary cholesterol is equivalent to the endogenous cholesterol synthesis rate and resulted in hypercholesterolaemia, in contrast to the cholesterol-free diet. However, we cannot completely rule out the suggestion that the statistical power to detect a significant lowering of LDL cholesterol was too low, and therefore no clear dose-response effect was detectable. Another conceivable explanation could be that the hamster may be less sensitive and may respond less well than certain other species, including man. So far, only a few human studies have directly evaluated a dose-response relationship between sterol and stanol intake and cholesterol-lowering efficacy. They did not demonstrate a strong dose dependency (Miettinen \& Vanhanen, 1994; Hendriks et al. 1999; Nguyen et al. 1999; Hallikainen et al. 2000). In these studies, a doubling of sterol or stanol intake did not result in a corresponding doubling of TC and LDL cholesterol reduction. Moreover, a previous hamster study also did not find significant differences in plasma cholesterol lowering by $0.01,0.2$ and $1 \%$ sitostanol (Ntanios \& Jones, 1998). Taken together, this indicates that the relationship between doses of plant sterol or stanol ester intake and plasma cholesterol reduction may not be linear, at least at these levels of intake. A plausible explanation for the lack of a clear dose response is the compensatory increase in cholesterol synthesis with higher doses of sterol and stanol esters (Jones et al. 2000), which appears to reduce the lowering of LDL cholesterol. Although dose dependency may be shallow, these data clearly demonstrate that sterol and stanol esters are effective in cholesterol lowering at these doses.

Faecal cholesterol excretion was significantly enhanced in hamsters fed on the diets enriched with sterol and stanol esters. This was possibly caused by diminished intestinal cholesterol absorption, which is thought to be the major mechanism for the cholesterol-lowering action of sterols and stanols, as reported by others (Ikeda et al. 1988; Miettinen \& Vanhanen, 1994; Vanhanen et al. 1994; Weststrate et al. 1999). Previous findings suggest that intestinal cholesterol absorption is reduced, and subsequently cholesterol excretion is more effectively increased, by stanols compared to sterols (Sugano et al. 1977; Ikeda \& Sugano, 1978; Heinemann et al. 1993). Recent human studies, however, did not find a difference in inhibition of cholesterol absorption (Jones et al. 2000; Normen et al. 2000). In this hamster study, the esterified sterols and stanols had a comparable effect on increasing daily faecal cholesterol excretion, suggesting that possibly cholesterol absorption was diminished to the same extent by sterols and stanols.

It has been suggested that sterols may also regulate cholesterol metabolism through directly affecting key enzymes that regulate cholesterol metabolism and excretion (Shefer et al. 1973; Ikeda \& Sugano, 1983; Ling \& Jones, 1995a). Therefore, a particular focus of the present hamster study was to address effects on bile acid metabolism, i.e. bile acid excretion, hepatic synthesis, biliary lipid and bile acid composition. Reported effects on bile acid synthesis are conflicting. In rats, infusion of $\beta$-sitosterol inhibited (Boberg et al. 1989; Shefer et al. 1994), while dietary administration increased the activity of cholesterol $7 \alpha$-hydroxylase (Shefer et al. 1973). In the present hamster study, cholesterol $7 \alpha$-hydroxylase activity did not differ among the dietary groups, suggesting no influence of sterols, stanols and dimethylsterols on bile acid synthesis in the liver. Moreover, faecal bile acid excretion was also not affected by these treatments. Previous animal and human studies have reported discrepant effects of dietary sterols or stanols on faecal excretion of bile acids, but most studies revealed only minor or no changes (Jones et al. 1997; Weststrate et al. 1999). Therefore, these findings indicate that sterols do not impair the enterohepatic circulation of bile acids. In addition, a previous human study demonstrated that plant sterol esters did not alter the faecal concentration of secondary bile acids (Weststrate et al. 1999). This is in line with our findings that the ratio of primary:secondary bile acids in gallbladder bile was not altered by sterols or stanols.

The effects on biliary lipids and the bile acid profile of gallbladder bile was also investigated in the present hamster study. Feeding hamsters with dietary cholesterol usually results in a reduction in the molar ratio of biliary lipids and in changes in the bile acid profile due to a marked increase in chenodeoxycholate (Trautwein et al. $1993 b$, 1997). This is associated with the high prevalence of cholesterol gallstones in the cholesterol-fed hamster model. The effect has been linked to an inhibition of the activity of $12 \alpha$-hydroxylase, a key enzyme in the synthesis of cholic acid (Kuroki et al. 1983). Apparently, feeding 
sterols and stanols tended to reverse at least partly this cholesterol-induced effect, since cholate: chenodeoxycholate was improved. Similar findings, e.g. an increase in the molar percentage of cholate and a decrease in chenodeoxycholate, have been reported in mice fed $\beta$-sitosterol (Uchida et al. 1984). The observed changes in biliary cholate:chenodeoxycholate were small, but statistically significant (20-30\% increase); however, their full physiological significance is not fully interpretable and remains to be further elucidated.

The molar percentages of biliary lipids, i.e. cholesterol, PL and bile acids, were mostly unchanged, except for a significant decrease in the molar percentage of $\mathrm{BC}$ found in gallbladder bile of hamsters fed the stanol-supplemented diets. Although not a primary aspect of this study, the improved cholate:chenodeoxycholate together with the lower molar percentage of BC seen in this hamster model could indicate a gallstone preventive effect. However, effects of plant sterols and stanols on BC saturation in man are inconsistent (Begemann et al. 1978; Tangedahl et al. 1979). Nevertheless, in a recent human study, bile acid composition and the molar percentage of $\mathrm{BC}$ were unchanged after consumption of plant stanol esters, indicating that potential gallstone formation is unlikely or might even be prevented by plant sterols or stanols (Miettinen et al. 2000).

In conclusion, esters of desmethylsterols were as effective as esters of desmethylstanols in lowering plasma TC and LDL cholesterol in cholesterol-fed hamsters without affecting HDL cholesterol, while 4,4'dimethylsterols from rice bran oil were less effective. Enhanced faecal cholesterol excretion caused by an inhibition of intestinal cholesterol absorption appeared to be the main mechanism for the cholesterol-lowering action of desmethylsterols and -stanols, while enhanced faecal bile acid excretion and stimulation of bile acid synthesis did not appear to be involved. For 4,4'-dimethylsterols, other not yet fully evident mechanisms need to be considered to explain their modest cholesterol-lowering effect.

\section{Acknowledgements}

The authors thank Swantje Möller and Claire Mermet for their excellent technical assistance and help with animal care, and Dr Fady Ntanios and Dr Mike Rudrum for helpful comments on the manuscript.

This study was supported in part by a grant of Unilever Research, Vlaardingen, The Netherlands. Presented in parts at the Experimental Biology 2001 meeting in Orlando, Florida, March 31-April 4, 2001; FASEB Journal, abstract \#238.13, p. A275.

\section{References}

Begemann F, Bandomer G \& Herget HJ (1978) The influence of beta-sitosterol on biliary cholesterol saturation and bile acid kinetics in man. Scandinavian Journal of Gastroenterology 13, $57-63$.
Boberg KM, Akerlund J-E \& Björkhem I (1989) Effect of sitosterol on the rate-limiting enzymes in cholesterol synthesis and degradation. Lipids 24, 9-12.

Chiang JYL (1991) Reversed-phase high-performance liquid chromatography assay of cholesterol $7 \alpha$-hydroxylase. Methods of Enzymology 206, 483-491.

DeDeckere EAM \& Korver O (1996) Minor constituents of rice bran oil as functional foods. Nutrition Reviews 54, S120-S126.

Goulinet S \& Chapman MJ (1993) Plasma lipoproteins in the golden Syrian hamster (Mesocricetus auratus): heterogeneity of apo B- and apo $\mathrm{A}_{1}$-containing particles. Journal of Lipid Research 34, 943-959.

Gylling H \& Miettinen TA (1996) Effects of inhibiting cholesterol absorption and synthesis on cholesterol and lipoprotein metabolism in hypercholesterolemic non-insulin dependent diabetic men. Journal of Lipid Research 37, $1776-1785$.

Gylling H, Siimes MA \& Miettinen TA (1995) Sitostanol ester margarine in dietary treatment of children with familiar hypercholesterolemia. Journal of Lipid Research 36, 1807-1812.

Hallikainen MA, Sarkkinen ES \& Uusitupa MIJ (2000) Plant stanol esters affect serum cholesterol concentrations of hypercholesterolemic men and women in a dose-dependent manner. Journal of Nutrition 130, 767-776.

Havel RJ, Eder HA \& Bragdon JH (1955) The distribution and chemical composition of ultracentrifugally separated lipoproteins in human serum. Journal of Clinical Investigation 34, $1345-1353$.

Hayes KC, Stephan ZF, Pronczuk A, Lindsey S \& Verdon C (1989) Lactose protects against estrogen-induced pigment gallstones in hamsters fed nutritionally adequate purified diets. Journal of Nutrition 119, 1726-1736.

Heinemann T, Axtmann G \& von Bergmann K (1993) Comparison of intestinal absorption of cholesterol with different plant sterols in man. European Journal of Clinical Investigation $\mathbf{2 3}, 827-831$.

Hendriks HFJ, Weststrate JA, Van Vliet T \& Meijer GW (1999) Spreads enriched with three different levels of vegetable oil sterols and the degree of cholesterol lowering in normocholesterolaemic and mildly hypercholesterolaemic subjects. European Journal of Clinical Nutrition 153, 319-327.

Hylemon PB, Studer EJ, Pandak WM, Heuman DM, Vlahcevic ZR \& Chiang JYL (1989) Simultaneous measurement of cholesterol $7 \alpha$-hydroxylase activity by reversed-phase high performance liquid chromatography using both endogenous and exogenous $\left[4-{ }^{14} \mathrm{C}\right]$ cholesterol as substrate. Analytical Biochemistry 182, 212-216.

Ikeda I, Kawasaki A, Samezima K \& Sugano M (1981) Antihypercholesterolemic activity of $\beta$-sitostanol in rabbits. Journal of Nutritional Science and Vitaminology 27, 243-251.

Ikeda I, Nakashima-Yoshida K \& Sugano M (1985) Effects of cycloartenol on absorption and serum levels of cholesterol in rats. Journal of Nutritional Science and Vitaminology 31, 375-384.

Ikeda I \& Sugano M (1978) Comparison of absorption and metabolism of $\beta$-sitosterol and $\beta$-sitostanol in rats. Atherosclerosis 30, 227-237.

Ikeda I \& Sugano M (1983) Some aspects of mechanism of inhibition of cholesterol absorption by $\beta$-sitosterol. Biochimica et Biophysica Acta 732, 651-658.

Ikeda I, Tanaka K, Sugano M, Vahouny GV \& Gallo LL (1988) Inhibition of cholesterol absorption in rats by plant sterols. Journal of Lipid Research 29, 1573-1582.

Imray CHE, Minoura T, Davis A, Radley S, Newbold KM, Lavelle-Jones M, Lawson AM, Baker PR \& Neoptolemos JP (1992) Comparability of hamsters with human faecal 
unconjugated bile acids in a model of colorectal cancer. Anticancer Research 12, 553-558.

Jones PJH, MacDougall DE, Ntanios F \& Vanstone C (1997) Dietary phytosterols as cholesterol-lowering agents in humans. Canadian Journal of Physiology and Pharmacology $\mathbf{7 5}$, 217-227.

Jones PJH, Raeini-Sarjaz M, Ntanios F, Vanstone CA, Feng JY \& Parsons W (2000) Modulation of plasma lipid levels and cholesterol kinetics by phytosterol versus phytostanol esters. Journal of Lipid Research 41, 697-705.

Kris-Etherton PM \& Dietschy J (1997) Design criteria for studies examining individual fatty acid effects on cardiovascular disease risk factors: human and animal studies. American Journal of Clinical Nutrition 65, Suppl., 1590S-1596S.

Kuroki S, Muramoto S, Kuramoto T \& Hoshita T (1983) Effect of feeding cholesterol and sitosterol on hepatic steroid $12 \alpha$ hydroxylase activity in female hamsters. Journal of Pharmcological Dynamics 6, 551-557.

Ling WH \& Jones PJH (1995a) Dietary phytosterols. A review of metabolism, benefits and side effects. Life Sciences 57, $195-206$.

Ling WH \& Jones PJH (1995b) Enhanced efficacy of sitostanolcontaining versus sitostanol-free phytosterols mixtures in altering lipoprotein cholesterol levels and synthesis in rats. Atherosclerosis 118, 319-331.

Markwell MAK, Haas SM, Bieber LL \& Tolbert NE (1978) A modification of the Lowry procedure to simplify protein determination in membrane and lipoprotein samples. Analytical Biochemistry 87, 206-210.

Miettinen TA, Puska P, Gylling H, Vanhanen H \& Vartiainen E (1995) Reduction of serum cholesterol with sitostanol-ester margarine in a mildly hypercholesterolemic population. New England Journal of Medicine 333, 1308-1312.

Miettinen TA \& Vanhanen HT (1994) Dietary sitosterol related to absorption, synthesis and serum levels of cholesterol in different apolipoprotein E phenotypes. Atherosclerosis 106, $217-226$

Miettinen TA, Vuoristo M, Nissinen M, Järvinen HJ \& Gylling H (2000) Serum, biliary, and fecal cholesterol and plant sterols in colectomized patients before and during consumption of stanol ester margarine. American Journal of Clinical Nutrition 71, $1095-1102$.

Nagao K, Sato M, Takenaka M, Ando M, Iwamoto M \& Imaizumi K (2001) Feeding unsaponifiable compounds from rice bran oil does not alter hepatic mRNA abundance for cholesterol metabolism-related proteins in hypercholesterolemic rats. Bioscience, Biotechnology \& Biochemistry 65, 371-377.

Nguyen TT, Dale LC, von Bergmann K \& Croghan IT (1999) Cholesterol-lowering effect of stanol ester in a US population of mildly hypercholesterolemic men and women: a randomized controlled trial. Mayo Clinic Proceedings 74, 1198-1206.

Normen L, Dutta P, Lia A \& Andersson H (2000) Soy sterol esters and $\beta$-sitostanol ester as inhibitors of cholesterol absorption in human small bowel. American Journal of Clinical Nutrition 71, 908-913.

Ntanios FY \& Jones PJ (1998) Effects of variable dietary sitostanol concentrations on plasma lipid profile and phytosterol metabolism in hamsters. Biochimica et Biophysica Acta 1390, 237-244.

Pollak OJ \& Kritchevsky D (1981) Sitosterol. In Monographs on Atherosclerosis, Vol. 10, [TB Clarkson and D Kritchevsky, editors]. New York, Basel: Karger.

Rossi SS, Converse JL \& Hofmann AF (1987) High pressure liquid chromatographic analysis of conjugated bile acids in human bile: simultaneous resolution of sulfated and unsulfated lithocholyl amidates and the common conjugated bile acids. Journal of Lipid Research 28, 589-595.
Shefer S, Hauser S, Lapar V \& Mosbach EH (1973) Regulatory effects of sterols and bile acids on hepatic 3-hydroxy3 -methylglutaryl CoA reductase and cholesterol $7 \alpha$-hydroxylase in the rat. Journal of Lipid Research 14, 573-580.

Shefer S, Salen G, Bullock J, Nguyen LB, Ness GC, Vhao Z, Belamarich PF, Chowdhary I, Lerner S, Batta AK \& Tint GS (1994) The effect of increased hepatic sitosterol on the regulation of 3-hydroxy-3-methylglutaryl-coenzyme A reductase and cholesterol $7 \alpha$-hydroxylase in the rat and sitosterolemic homozygotes. Hepatology 20, 213-219.

Sierksma A, Weststrate JA \& Meijer GW (1999) Spreads enriched with plant sterols, either esterified 4,4 dimethylsterols or free 4-desmethylsterols, and plasma total and LDLcholesterol concentrations. British Journal of Nutrition 82, 273-282.

Spady DK, Stange EF, Bilhartz LE \& Dietschy JM (1986) Bile acids regulate hepatic low density lipoprotein receptor activity in the hamster by altering cholesterol flux across the liver. Proceedings of the National Academy Sciences USA 83, 1916-1920.

Spady DK, Turley SD \& Dietschy JM (1985) Rates of low density lipoprotein uptake and cholesterol synthesis are regulated independently in the liver. Journal of Lipid Research 26, $465-472$.

Suckling KE, Benson GM, Bond B, Gee A, Glen A, Haynes C \& Jackson B (1991) Cholesterol lowering and bile acid excretion in the hamster with cholestyramine treatment. Atherosclerosis 89, 183-190.

Sugano M, Kamo F, Ikeda I \& Morioka H (1976) Lipidlowering activity of phytostanols in rats. Atherosclerosis $\mathbf{2 4}$, 301-309.

Sugano M, Morioka H \& Ikeda I (1977) A comparison of hypocholesterolemic activity of $\beta$-sitosterol and $\beta$-sitostanol in rats. Journal of Nutrition 107, 2011-2019.

Sugano M \& Tsuji E (1997) Rice bran oil and cholesterol metabolism. Journal of Nutrition 127, 521S-524S.

Tangedahl TN, Thiste JL, Hofmann AF \& Matsehe JW (1979) Effect of beta-sitosterol alone or in combination with chenic acid on cholesterol saturation of bile and cholesterol absorption in gallstones patients. Gastroenterology 76, 1341-1346.

Trautwein EA, Kunath-Rau A, Dietrich J, Drusch S \& Erbersdobler HF (1997) Effect of dietary fats rich in lauric, myristic, palmitic, oleic or linoleic acid on plasma, hepatic and biliary lipids in cholesterol-fed hamsters. British Journal of Nutrition 77, 605-620.

Trautwein EA, Liang J \& Hayes KC (1993a) Cholesterol gallstone induction in hamsters reflect strain differences in plasma lipoproteins and bile acid profiles. Lipids 28, 305-312.

Trautwein EA, Siddiqui A \& Hayes KC (1993b) Modeling plasma lipoprotein-bile lipid relationships: differential impact of psyllium and cholestyramine in hamsters fed a lithogenic diet. Metabolism 42, 1531-1540.

Uchida K, Takase H, Nomura Y, Takeda K, Takeuchi N \& Ishikawa Y (1984) Changes in biliary and fecal bile acids in mice after treatments with diosgenin and $\beta$-sitosterol. Journal of Lipid Research 25, 236-245.

Vanhanen HT, Kajander J, Lehtovirta H \& Miettinen TA (1994) Serum levels, absorption efficiency, faecal elimination and synthesis of cholesterol during increasing doses of dietary sitostanol esters in hypercholesterolaemic subjects. Clinical Science 87, 61-67.

Vissers MN, Zock PL, Meijer GW \& Katan MB (2000) Effect of plant sterols from rice bran oil and triterpene alcohols from sheanut oil on serum lipoprotein concentrations in humans. American Journal of Clinical Nutrition 72, 1510-1515.

Weststrate JA, Ayesh R, Bauer-Plank C \& Drewitt PN (1999) 
Safety evaluation of phytosterol esters. Part 4. Faecal concentrations of bile acids and neutral sterols in healthy normolipidaemic volunteers consuming a controlled diet either with or without a phytosterol ester-enriched margarine. Food and Chemistry Toxicology 37, 1063-1071.
Weststrate JA \& Meijer GW (1998) Plant sterol-enriched margarines and reduction of plasma total and LDL-cholesterol concentrations in normocholesterolemic and mildly hypercholesterolemic subjects. European Journal of Clinical Nutrition 52, 334-343. 